\title{
Monitoring the Obesity Epidemic into the 21st Century - Weighing the Evidence
}

\author{
Lauren Lissner $^{a}$ Tommy L.S. Visscher ${ }^{b} \quad$ Aila Rissanen $^{c}$ \\ Berit L. Heitmann d, e for the Prevention and Public Health Task Force of \\ the European Association for the Study of Obesity \\ ${ }^{a}$ Department of Public Health and Community Medicine/ Public Health Epidemiology, \\ EpiLife Resaearch Center, Sahlgrenska Academy at University of Gothenburg, Gothenburg, \\ Sweden, ${ }^{\mathrm{b}}$ Research Center for the Prevention of Overweight, VU Windesheim, Zwolle, the \\ Netherlands, ${ }^{c}$ Helsinki University Central Hospital, Helsinki, Finland, ${ }^{\mathrm{d}}$ Institute of Preventive \\ Medicine, Bispebjerg and Frederiksberg Hospitals - a part of Copenhagen University \\ Hospital, the Capital Region, and National Institute of Public Health, University of Southern \\ Denmark, Copenhagen, Denmark, ${ }^{\mathrm{e} T h e}$ Boden Institute of Obesity, Nutrition, Exercise \& \\ Eating Disorders, The University of Sydney, Sydney, Australia,
}

According to recent literature the obesity epidemic in adults and particularly in children seems to have stabilized or receded since the end of the 20th century [1,2]. Many of the encouraging trends toward stabilization have occurred simultaneously in different parts of the world. However, there may be some biases in the data being reported that could explain these trends, to which we will draw attention in the sections below. Besides statistical biases and distortions in the data itself, there may be interpretation biases of a less statistical nature. This paper is not intended to systematically review all publications on the course of the epidemic or discuss study-specific biases in detail, but rather intends to highlight the most relevant sources of bias while offering selected examples of such biases from the literature.

We will first review several classic sources of bias in survey data describing secular trends in obesity, which have been frequently discussed in terms of how they might affect conclusions regarding the course of the obesity epidemic. In addition, we will describe sources of bias in what we are looking at and how we are looking at it, which may distort conclusions regarding the obesity epidemic.

\section{Change in Participation Rate}

If obesity rates were truly increasing, could decreasing participation rates explain the stable or decreasing prevalence observed? There is a wealth of literature on obesity related non-participation [3-6]. A number of studies have found no increase in obesity and stable 
participation rates [e.g., 7]. There are however exceptions where obesity rates were stable while participation decreased dramatically [e.g., 8]. From the latter example, it could be argued that increasing non-participation is masking true increases in obesity over time.

\section{Self-Reported versus Measured Data}

It is well known that body weight is underreported and that the problem increases with increasing BMI. Is the problem that self-reported weight for height data [e.g., 9-11] become increasingly biased when more people are obese and therefore more people underreport their weights? If the underreporting of BMI is increasing with time, this could hide secular trends in obesity. In contrast most studies in children are not based on self-reported weights but on surveys in schools or primary health care centers. Therefore, this type of bias is more likely in adults.

\section{Random Fluctuation}

One example of non-systematic error occurs due to lack of standardized measurement and sampling protocols and varying error across different studies. This problem may be somewhat mitigated if multiple time points are available. In contrast, only two observation points are more likely to give a false impression of change, compared to long-term trends with enough observations to rule out random fluctuations. The counter-argument here would be that most of our observations occurred during the same decade so the stability can hardly be purely random.

\section{Right Skewed Data}

Failure to detect changes in the total prevalence of obesity or mean BMI may hide large differences in the right extreme of the distribution. For example, studies in Danish draftees showed much larger increases in extreme obesity than in moderate obesity or BMI per se [12]. In contrast, a study in NHANES found similar lack of trends in the mid- and extreme parts of the distribution [13]. Researchers should continue to examine full distributions rather than central tendencies and avoid basing conclusions exclusively on cut-point-based definitions.

\section{Unrepresentative Sampling}

The rural-to-urban shift may be hiding increases in obesity given that many surveys are conducted in larger cities. Data from Denmark indicate that urban areas have had the greatest increase in educational level and rural areas the lowest, which would result in biased estimates if surveys are conducted in urban areas [14]. However, the NHANES studies (both in adults and children) are counter-examples since sampling procedures are designed to be representative $[13,15]$. Also the recent Swedish data (though self-reported) are based on nationally representative sampling and show few if any trends in obesity [10]. 


\section{Over-Aggregation Leading to Overgeneralization}

Presenting aggregated data on trends in obesity in all social groups combined may hide differential trends in low versus high socioeconomic status (SES) groups and lead to the conclusion that all is well, when the situation may be worsening in some parts of the population. In British and French children, there has been evidence that the gap is shifting $[16,17]$. In two Swedish studies $[7,18]$, patterns of secular trends varied in urban boys of different SES backgrounds although the aggregated data showed no overall trend in boys. However, other studies have shown stable socioeconomic gradients over time in Finnish adolescents [19] and in French children [20]. There is also evidence for gender differences in this phenomenon, i.e., in both Swedish studies described above girls in all social groups displayed trends in the same (decreasing) direction. Finally, studies both in the USA and the Netherlands confirm that certain minority groups continue to experience increasing obesity in their children, while the rest of the population appears stable [21,22]. It is often observed that a higher susceptibility in less advantaged groups results in greater increases in these groups over time. However, the difference could be in the other direction, with increases in the more advantaged groups where obesity has not yet fully penetrated or 'saturation' has not occurred.

\section{Obesity Topography Not Considered in BMI}

BMI may not be capturing a particularly dangerous aspect of the epidemic, which is increasing central obesity. An early study from Sweden showed that during a period of no increases in BMI, waist-to-hip ratio increased dramatically in 38- and 50-year-old women [23]. This finding was subsequently reproduced in Finnish adults [24]. A later study from MONICA, Gothenburg, showed that although BMI in men was increasing more than in women, waist-to-hip ratio increased more dramatically in women from 1985 to 2001 [25]. Similar observations have been made in children [26, 27]. Another body shape consideration involves height: there have been secular increases in height in most populations during the periods of rising and then stabilizing obesity rates, which may have blunted the severity of the epidemic as well as exerting heavy influence in the denominator of BMI calculations.

\section{Publication Bias}

It is well recognized that small studies reporting novel findings are often published and thereby contribute to publication bias. However, since the increase in obesity is old news, it is plausible that a disproportionate number of studies reporting stable and decreasing trends are appearing. However, regarding sample size there are both larger and smaller studies showing similar results. In this case, the bias might be both due to inherent features in the data, i.e. small studies, but particularly how we are interpreting the meta-literature. It has been proposed that the phenomenon of publication bias is highly prevalent in the obesity research field [28], perhaps even more so than in other fields that are less in the public eye.

\section{Weighing the Evidence}

As pointed out in 2001 in an article entitled 'Causation of Bias: The Episcope' [29] biases in all areas of epidemiology can occur at many levels and points in time in an investigation ranging from choosing the research question, to defining the measurement and sampling 
procedures, to analyzing the data, to publishing the results. This situation is well illustrated in the present paper. Although some of the biases listed here seem less plausible than others, these must be weighed when considering the sum of the evidence. Given the crucial importance of the topic, surveillance with standardized sampling and methodology is warranted in Europe, as proposed by the WHO [30]. On the whole however, the available trend data seem to stand up to scrutiny concerning the most plausible biases and interpretational errors, as discussed in an upcoming full article which will look into these issues in more detail [31].

Finally, a commentary on potential biases would be incomplete without considering alternative explanations for the apparently stabilizing rates of obesity. First, it must be acknowledged that these observations may be due to an unknown environmental factor which is not yet understood. Other explanations, also discussed by Olds et al. in [2], include i) a saturation effect whereby most susceptible individuals became obese during the epidemic, ii) a population-based intervention effect whereby lifestyles are becoming less obesogenic, or iii) various biases, which were the focus of this commentary.

\section{Acknowledgement}

This commentary is a summary of a debate organized by the European Association for the Study of Obesity (EASO), at the International Congress of Obesity in 2010, in Stockholm. In this debate, moderated by TLSV and AR, LL argued that the epidemic is leveling off and BLH argued that apparent trend could be explained by biases.

\section{References}

1 Rokholm B, Baker JL, Sorensen TI: The levelling off of the obesity epidemic since the year 1999 - a review of evidence and perspectives. Obes Rev 2010;11:835-846.

2 Olds T, Maher C, Zumin S, Peneau S, Lioret S, Castetbon K, et al: Evidence that the prevalence of childhood overweight is plateauing: data from nine countries. Int J Pediatr Obes 2011;6:342-360.

-3 Sonne-Holm S, Sorensen TI, Jensen G, Schnohr P: Influence of fatness, intelligence, education and sociodemographic factors on response rate in a health survey. J Epedimol Commun Health 1989;43:369-374.

$>4$ Bengtsson C, Ahlqwist M, Andersson K, Bjorkelund C, Lissner L, Soderstrom M: The Prospective Population Study of Women in Gothenburg, Sweden, 1968-69 to 1992-93. A 24-year follow-up study with special reference to participation, representativeness, and mortality. Scand J Prim Health Care 1997;15:214-219.

$\checkmark 5$ Lewis CE, Jacobs DR Jr, McCreath H, Kiefe CI, Schreiner PJ, Smith DE, et al: Weight gain continues in the 1990s: 10 -year trends in weight and overweight from the CARDIA study. Coronary Artery Risk Development in Young Adults. Am J Epidemiol 2000;151:1172-1181.

6 Lissner L, Skoog I, Andersson K, Beckman N, Sundh V, Waern M, et al: Participation bias in longitudinal studies: experience from the Population Study of Women in Gothenburg, Sweden. Scand J Prim Health Care 2003;21: 242-247.

7 Sjoberg A, Lissner L, Albertsson-Wikland K, Marild S: Recent anthropometric trends among Swedish school children: evidence for decreasing prevalence of overweight in girls. Acta Paediatr 2008;97:118-123.

-8 Lissner L, Sjoberg A, Schutze M, Lapidus L, Hulthen L, Bjorkelund C: Diet, obesity and obesogenic trends in two generations of Swedish women. Eur J Nutr 2008;47:424-431.

-9 Kuskowska-Wolk A, Karlsson P, Stolt M, Rossner S: The predictive validity of body mass index based on selfreported weight and height. Int J Obes 1989;13:441-453.

10 Sundquist J, Johansson SE, Sundquist K: Levelling off of prevalence of obesity in the adult population of Sweden between 2000/01 and 2004/05. BMC Public Health 2010;10:119.

11 Lissner L, Johansson SE, Qvist J, Rossner S, Wolk A: Social mapping of the obesity epidemic in Sweden. Int J Obes Relat Metab Disord 2000;24:801-805.

12 Thomsen BL, Ekstrom CT, Sorensen TI: Development of the obesity epidemic in Denmark: cohort, time and age effects among boys born 1930-1975. Int J Obes Relat Metab Disord 1999;23:693-701.

13 Flegal KM, Carroll MD, Kit BK, Ogden CL: Prevalence of obesity and trends in the distribution of body mass index among US adults, 1999-2010. JAMA 2012;307:491-497.

14 Indenrigs- og Sundhedsministeriet: Regionalpolitisk redegørelse 2005. Copenhagen, Indenrigs- og Sundhedsministeriet, 2005. www.sm.dk/data/Dokumentertilpublikationer/IM/Regionalpolitisk_redeg\%C3\%B8relse_ analyse_og_baggrund2005/2051129_redegoerelsespubl.pdf(last accessed November 27. 2013). 
Lissner et al.: Monitoring the Obesity Epidemic into the 21st Century - Weighing the Evidence

15 Ogden CL, Carroll MD, Flegal KM: High body mass index for age among US children and adolescents, 20032006. JAMA 2008;299:2401-2405.

16 Brunt H, Lester N, Davies G, Williams R: Childhood overweight and obesity: is the gap closing the wrong way? J Public Health (Oxf) 2008;30:145-152.

-17 Romon M, Duhamel A, Collinet N, Weill J: Influence of social class on time trends in BMI distribution in 5-year-old French children from 1989 to 1999. Int J Obes (Lond) 2005;29:54-59.

18 Sundblom E, Petzold M, Rasmussen F, Callmer E, Lissner L: Childhood overweight and obesity prevalences levelling off in Stockholm but socioeconomic differences persist. Int J Obes (Lond) 2008;32:1525-1530.

-19 Kautiainen S, Koivisto AM, Koivusilta L, Lintonen T, Virtanen SM, Rimpela A: Sociodemographic factors and a secular trend of adolescent overweight in Finland. Int J Pediatr Obes 2009;4:360-370.

20 Lioret S, Touvier M, Dubuisson C, Dufour A, Calamassi-Tran G, Lafay L, et al: Trends in child overweight rates and energy intake in France from 1999 to 2007:relationships with socioeconomic status. Obesity (Silver Spring) 2009;17:1092-1100.

21 de Wilde JA, van Dommelen P, Middelkoop BJ, Verkerk PH: Trends in overweight and obesity prevalence in Dutch, Turkish, Moroccan and Surinamese South Asian children in the Netherlands. Arch Dis Child 2009;94: 795-800.

$\checkmark 22$ Centers for Disease Control and Prevention (CDC): Obesity prevalence among low-income, preschool-aged children - United States, 1998-2008. MMWR Morb Mortal Wkly Rep 2009;58:769-773.

-23 Lissner L, Bjorkelund C, Heitmann BL, Lapidus L, Bjorntorp P, Bengtsson C: Secular increases in waist-hip ratio among Swedish women. Int J Obes Relat Metab Disord 1998;22:1116-1120.

24 Lahti-Koski M, Harald K, Mannisto S, Laatikainen T, Jousilahti P: Fifteen-year changes in body mass index and waist circumference in Finnish adults. Eur J Cardiovasc Prev Rehabil 2007;14:398-404.

25 Berg C, Rosengren A, Aires N, Lappas G, Toren K, Thelle D, et al: Trends in overweight and obesity from 1985 to 2002 in Goteborg, West Sweden. Int J Obes (Lond) 2005;29:916-924.

26 Moreno LA, Fleta J, Sarria A, Rodriguez G, Gil C, Bueno M: Secular changes in body fat patterning in children and adolescents of Zaragoza (Spain), 1980-1995. Int J Obes Relat Metab Disord 2001;25:1656-1660.

27 McCarthy HD, Ellis SM, Cole TJ: Central overweight and obesity in British youth aged 11-16 years: cross sectional surveys of waist circumference. BMJ 2003;326:624.

28 Cope MB, Allison DB: White hat bias: examples of its presence in obesity research and a call for renewed commitment to faithfulness in research reporting. Int J Obes (Lond) 2010;34:84-88; discussion 83.

29 Maclure M, Schneeweiss S: Causation of bias: the episcope. Epidemiology 2001;12:114-122.

30 Wijnhoven TM, van Raaij JM, Spinelli A, Rito AI, Hovengen R, Kunesova M, et al: WHO European Childhood Obesity Surveillance Initiative 2008: weight, height and body mass index in 6-9-year-old children. Pediatr Obes 2013;8:79-97.

31 Visscher TLS, Heitmann BL, Rissanen A, Lahti-Koski M, Lissner L: A break in the obesity epidemic? Explained by biases or wrong interpretation of the data? Int J Obes 2014 (under revision). 